
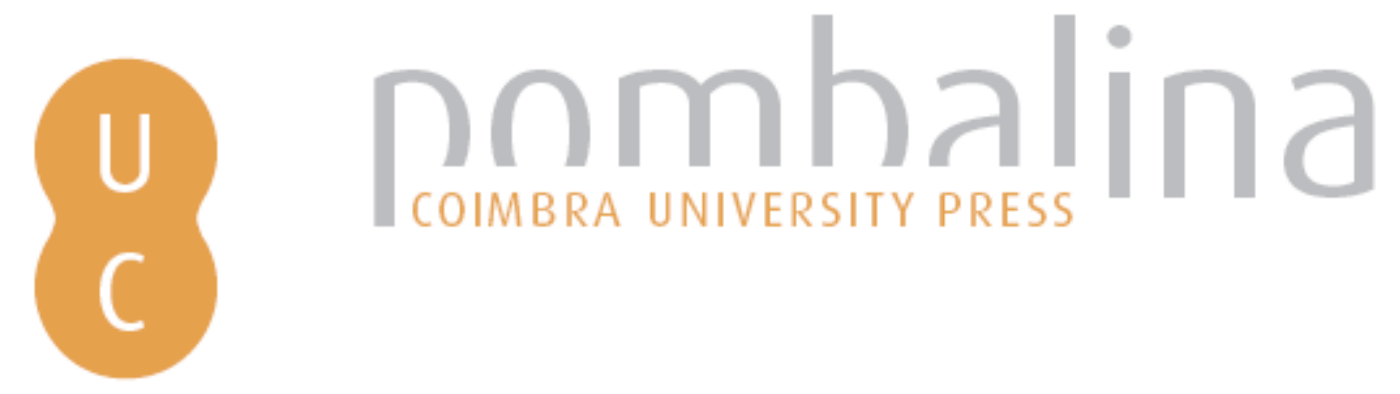

\title{
Nota da associação dos antigos alunos do Liceu da Horta
}

Autor(es): Barreiros, Henrique Melo

Publicado por: Imprensa da Universidade de Coimbra

URL

persistente:

URI:http://hdl.handle.net/10316.2/31188

DOI:

DOI:http://dx.doi.org/10.14195/978-989-26-0437-4_2

Accessed : $\quad$ 26-Apr-2023 14:39:17

A navegação consulta e descarregamento dos títulos inseridos nas Bibliotecas Digitais UC Digitalis, UC Pombalina e UC Impactum, pressupõem a aceitação plena e sem reservas dos Termos e Condições de Uso destas Bibliotecas Digitais, disponíveis em https://digitalis.uc.pt/pt-pt/termos.

Conforme exposto nos referidos Termos e Condições de Uso, o descarregamento de títulos de acesso restrito requer uma licença válida de autorização devendo o utilizador aceder ao(s) documento(s) a partir de um endereço de IP da instituição detentora da supramencionada licença.

Ao utilizador é apenas permitido o descarregamento para uso pessoal, pelo que o emprego do(s) título(s) descarregado(s) para outro fim, designadamente comercial, carece de autorização do respetivo autor ou editor da obra.

Na medida em que todas as obras da UC Digitalis se encontram protegidas pelo Código do Direito de Autor e Direitos Conexos e demais legislação aplicável, toda a cópia, parcial ou total, deste documento, nos casos em que é legalmente admitida, deverá conter ou fazer-se acompanhar por este aviso.

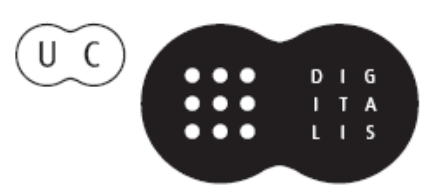




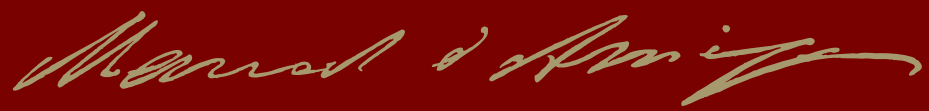

-

-

-

-

-

-

○

-

-

-

-

-

-

-

-

-

-

- 


\section{NOTA DA ASSOCIAÇÃ̃O DOS ANTIGOS ALUNOS DO LICEU DA HORTA}

Henrique Melo Barreiros 
(Página deixada propositadamente em branco) 
É certamente curioso ver uma pequena associação cívica ligada à evocação de um tempo da história da Universidade de Coimbra, com a honrosa prerrogativa de ter sido aceite a sua colaboração.

Por isso, será natural, e até necessária, uma nota explicativa sobre a história do envolvimento da Associação dos Antigos Alunos do Liceu da Horta no estudo e na reanálise da memória de Manuel de Arriaga, bem como na evocação dos tempos marcantes do seu percurso de vida pública.

\section{1 - Grandeza e esquecimentos de Manuel de Arriaga}

O primeiro Reitor da Universidade de Coimbra na República nasceu na ilha do Faial (1840), no Solar dos Arriaga, casa senhorial no centro da cidade da Horta, desfrutando de uma privilegiada relação com a natureza, através dos seus jardins históricos e de uma quinta urbana tradicional. Aqui, até ingressar na Faculdade de Direito, o jovem Arriaga, em ambiente erudito e cosmopolita, acedeu à educação e despertou para a cultura que sempre o distinguiram ao longo da vida. Na estatura moral, na coragem política, 
na sensibilidade do poeta romântico, no fulgor do tribuno ou na contemplação do pensador de uma nova ordem humanista universal.

O Solar dos Arriaga continuou durante muitos anos uma referência social e cultural da sociedade faialense. E o filho Manuel prosseguia a sua vida em Coimbra e em Lisboa, de forma dura, exemplar, brilhante. Diversificada mas convergente na luta pela república e pela democracia. O Direito foi uma grande paixão, como causídico, jurista, autor de teses de âmbito forense, pensador da justiça, chegando a Procurador Geral da República. As questões de educação mobilizaram-no sempre, nas acções de propaganda e nas funções políticas por onde passou. Deixou uma obra vasta em poesia e em prosa, com mensagens diversas, em particular de filosofia social. A actividade política foi determinante ao longo de toda a sua vida, sempre de forma intensa, quando ainda estudante, depois no Partido Republicano, e ainda, como deputado com larga intervenção sobre variadíssimos temas, conhecido pela grande capacidade oratória; chegou a Presidente da República, devido à sua respeitabilidade histórica e à visão moderada para a mudança política em Portugal. Com poderes parcos e penúria de meios, atolado numa teia de radicalismos, mobilizados por interesses pessoais em proliferações partidárias, tenta consensos e ensaia soluções, até desesperadas. Perde nos jogos da política violenta. O país olha-o com respeito mas com embaraço. Faleceu em 1917. 
Entretanto, a terra natal revia-se no filho ilustre. A imprensa exaltava o seu percurso político. A edilidade cuidava das memórias iconográficas. Em 1918 o Governo designou-o patrono do Liceu da Horta.

Mais tarde o Solar dos Arriaga muda de proprietário - a Igreja Católica - e passa a ser um centro de convívio para os jovens faialenses. E o seu peso simbólico é ainda reforçado para muitas gerações porque ao entrarem nestes espaços lúdicos uma lápide recorda-lhes "Aqui nasceu o $1^{\circ}$ Presidente da República Portuguesa". Criou-se assim um imaginário heróico sobre Arriaga, uma empatia afectiva, de orgulho e admiração. O tempo foi passando até que em meados da década de 90 do século passado, a Associação dos Antigos Alunos do Liceu da Horta para assinalar os 150 anos do Liceu (criado pela reforma de Passos Manuel, 1836 e reconfirmado na revisão de Costa Cabral, 1842), decide preparar uma obra sobre a biografia do patrono, dedicada às novas gerações. Naturalmente, mas com alguma ingenuidade, era pressuposto que, atendendo à dimensão histórica da figura em causa, os suportes de memória, os estudos, as teses, estariam disponíveis. Desilusão. A historiografia portuguesa não tinha dedicado atenção a Arriaga. Cerca de 80 anos após ter sido anunciada a existência de um vasto espólio privado, este não fora organizado. Persistiam omissões e também deturpações. Era uma figura esquecida.

As comemorações dos 150 anos do Liceu passaram então a dar prioridade a um movimento de reabilitação da memória de 
Manuel de Arriaga, num percurso que merece ser aqui genericamente recordado

\section{2 - Reencontros com a memória de Manuel de Arriaga}

A existência de esquecimentos sobre Arriaga, as suas origens e hipóteses de interpretação, mereceram análise, concluindo-se ser necessário um processo de reparação. Convergindo com este movimento, a primeira grande iniciativa que veio trazer dados novos foi concentrada no arquivo privado e consequente publicação das obras sobre Correspondência politica e sobre Documentos políticos, coordenadas por Sérgio Campos Matos e participação na organização de Joana Gaspar de Freitas e Elisa Neves Travessa (na segunda), resultantes de acordo entre o fiel depositário do espólio, o bisneto de Arriaga Arq. J.M. Corrêa Guedes e o Centro de História da Universidade de Lisboa. O Colóquio "O Tempo de Manuel de Arriaga" foi o primeiro fórum de reflexão pluridisciplinar da biografia de Arriaga (Actas sob coordenação de Sérgio Campos Matos). As diligências para recuperar o esquecimento da classe política em conceder as honras de Panteão Nacional ao primeiro Presidente (depois de outros já terem recebido esta distinção) teve uma importância histórica crucial devido à reconciliação curiosa expressa por cada partido com assento parlamentar e a todo o processo de fundamentação 
(Cerimónia de Homenagem e Trasladação de Manuel de Arriaga, Assembleia da República; Manuel de Arriaga memórias para o futuro, AAALH). No primeiro trabalho científico em História Contemporânea sobre Manuel de Arriaga (Percurso intelectual e político de um republicano histórico), Joana Gaspar de Freitas introduziu nesta tese de mestrado grande maturidade na interpretação das fontes agora disponíveis, submetendo-as a uma reflexão crítica original.

De facto, entre 2000 e 2006, este foi o bloco de iniciativas verdadeiramente estruturantes de uma nova fase da historiografia sobre Manuel de Arriaga - organização e estudo do arquivo privado, realização do colóquio "O Tempo de Manuel de Arriaga", concessão de honras de Panteão e aprovação de uma tese académica na Universidade de Lisboa.

Entretanto, o resgate de esquecimentos seguiu linhas de orientação complementares: a reedição de publicações de Arriaga, a obra poética Cantos Sagrados e Harmonias Sociais e a publicação de trabalhos de divulgação, Bibliografia (activa e passiva) de Arriaga e História de um Açoriano que chegou a Presidente da República, biografia dirigida às novas gerações, ambos de Joana Gaspar de Freitas.

Merece referência, também, a evocação ou aprofundamento, já em tempo de Centenário, de circunstâncias esquecidas ou insuficientemente abordadas, tais como a dimensão de pensador em Harmonias Sociais, com estudo prévio de J. L. Brandão da Luz, 
também analisada por M. Cândido Pimentel (Manuel de Arriaga, um pensador na República, Revista Nova Águia) e a evocação do centenário da eleição do primeiro Presidente, esquecida dos programas oficiais (Manuel de Arriaga: um Pensamento de Verdade e de Justiça, Magda Costa Carvalho; Arriaga e o Julgamento da História, Luís Bigotte Chorão). Este movimento tem prosseguido destacando-se a inauguração da adaptação do Solar dos Arriaga a Casa-Memória (da responsabilidade do Governo Regional dos Açores), a publicação de uma obra fotobiográfica (Joana Gaspar de Freitas; Câmara Municipal da Horta) e, brevemente, a reedição da obra de Arriaga Na primeira presidência da República Portuguesa (Luís Bigotte Chorão e Joana Gaspar de Freitas; AAALH), com estudo introdutório e notas.

\section{3 - A missão de Manuel de Arriaga como Reitor da Universida- de de Coimbra}

No contexto deste movimento, percorrendo fontes, reanalisando factos e circunstâncias e mobilizando novos projectos historiográficos sobre o vasto património dos percursos de vida de Manuel de Arriaga, o tempo na Universidade de Coimbra, como Reitor, logo a seguir à revolução de 5 de Outubro, emergiu pela relevância histórica bem confinada. Relevância que não merecera ainda o devido destaque. 
Principalmente, percebeu-se que o pensamento comemorativo do Centenário da República não deveria esquecer a evocação desse tempo. Naturalmente, pela dimensão simbólica das singularidades que reúne mas, também, pela oportunidade de rever contextos históricos que aí se cruzam. Da $1^{a}$ República, porque estava presente mais um elemento fundamental do novo regime, a sua implantação na Universidade, órgão importante pela missão reprodutora de valores, conhecimento e mentalidades. Da Universidade de Coimbra, porque esta atravessava um tempo de passagem decisivo para o seu futuro exigindo a saída de um funcionamento obsoleto. Do próprio Arriaga, porque a sua história de vida recebe aqui claros alentos de auto-estima (como se assinala mais adiante).

Integrada a convicção da importância desta evocação e não se conhecendo qualquer outra diligência nesse sentido, foi apresentada proposta à Universidade de Coimbra que assumiu este projecto de reflexão sobre o seu passado com grande empenho institucional, sob a coordenação da Senhora Vice-Reitora para a Cultura, Professora Clara Almeida Santos, e com grande rigor científico, dado que, para a análise histórica do primeiro reitorado na república, foi convidado o Senhor Professor Luís Reis Torgal.

Depois da referência à história "afectiva" da ligação desta Associação à memória de Manuel de Arriaga e da breve abordagem ao essencial dos projectos realizados nesse âmbito, durante os últimos 10 anos, daremos um contributo directo sobre esta evocação do Reitor Manuel de Arriaga. 
Relativamente à nomeação, os sinais que se retiram de todo o contexto da época são elucidativos da importância excepcional que a situação mereceu - a reacção imediata do Governo Provisório poucos dias depois da sua entrada em funções, a escolha urgente de um novo Reitor e a realização da tomada de posse (duas semanas depois da Revolução) acompanhada em Coimbra pelo Ministro da tutela. A escolha do Governo é, de facto, um acto político excepcional - recorre a um republicano histórico, das mais prestigiadas figuras do período da propaganda republicana, apesar de já contar 70 anos. A situação exigia, portanto, um cuidado especial e esse tinha resposta em Arriaga, embora não partilhasse o discurso radical que inspirava o Governo Provisório. Sinal do acerto, pelo menos parcial, da escolha do Reitor pode ser encontrado no entusiasmo popular da recepção que teve em Coimbra (habitual nas intervenções públicas de Arriaga) e do qual o Governo através do Ministro António José de Almeida decerto tirou dividendos para a mudança política em curso.

Da acção concreta do Reitor esperamos que venha a ser possível assinalar a relação entre a missão que lhe foi pedida e a sua forma de a interpretar de acordo com o seu pensamento e experiência. Admitimos que terá sabido reduzir à insignificância os detractores que criticaram o facto de ter sido nomeado sem vir da carreira universitária (embora não fosse caso isolado na história da Universidade, tanto antes como na Primeira República). Para 
tanto, será necessário verificar se nas diferentes medidas existem sinais de uma intervenção consequente. Se algumas terão sido imperiosas outras terão decorrido da postura conhecida do Reitor a propósito do que estava em causa - uma nova Universidade! Imaginamos a sua habitual vontade mobilizadora da participação das pessoas, aqui, certamente, no combate à opressão ao livre pensamento e nos impulsos anunciadores da autonomia universitária (como a eleição do Reitor). Imaginamos também que o Reitor quisesse a Universidade aberta à comunidade.

Quanto à duração não se poderá falar de mandato reitoral mas de uma intervenção de emergência em que a Arriaga terá sido pedido possivelmente o funcionamento regular da Universidade e a preparação para uma nova forma de pensar o futuro, em coerência com toda a militância da sua vida pelos valores republicanos e democráticos e pelo primado da justiça e da ciência. Arriaga terá avisado o Governo do limite da sua participação (e recordado esse limite por carta, juntamente com o reparo sobre propostas suas que não teriam merecido atendimento célere). A sua idade era uma grande limitação que, no entanto, não tolhia a vitalidade para querer estar em Lisboa no centro da República que nascia e que tinha sido um dos maiores sonhos da sua vida. Recordemos que nessa altura já estava nomeado Procurador-Geral da República. E que foi integrar a Assembleia Nacional Constituinte presidindo às comissões de Negócios Estrangeiros e de Redacção. 
Apesar do esforço que deve ter constituído aceitar o pedido do Governo para esta missão extraordinária de acorrer a um tempo difícil da Universidade de Coimbra, contudo, se o cruzarmos com informação disponível sobre a vida pública e privada de Arriaga, encontramos razões de satisfação e realização pessoal para essa aceitação. Além de regressar a Coimbra, a que estava ligado por tantas recordações, principalmente, entrava pela porta grande numa instituição que nunca escondera, desde cedo, desejar integrar, e que lhe foi sempre vedada (embora noutras instituições de ensino superior), apesar do seu indiscutível valor intelectual e cultural. A escolha para Reitor é gratificante ainda por ver as suas capacidades reconhecidas pelo Governo Provisório presidido por um personagem que sempre lhe foi hostil (Teófilo de Braga). Cabe aqui uma referência à menorização da nomeação de Arriaga porque esta, sendo da responsabilidade directa de António José de Almeida, poderia remeter para a compensação de favores antigos quando este fora defendido em Tribunal por Arriaga. Para Arriaga terá sido assunto irrelevante. A sua estatura moral era reconhecida. A defesa de acusados de delito de opinião e presos políticos foi uma constante da sua conduta de advogado militante. Terá de admitir-se, no entanto, que a nomeação para Reitor pela República poderá querer significar o ressarcimento de uma injustiça da Monarquia. 
A concluir, é justo relembrar nesta Nota centrada nos esquecimentos que pendiam (pendem?) sobre Manuel de Arriaga, que a Universidade de Coimbra não se esqueceu do seu primeiro Reitor na República. Dedicou-lhe um in memoriam em 1917.

Hoje, em tempo de Centenário da República, porque evocar deve ser sempre uma repetição sem repetição, quando tantas hesitações nos interrogam sobre se, afinal, a História se repete, o apelo que nos anima é a necessidade de uma reflexão sobre as mensagens de Manuel de Arriaga enquanto Reitor para verificar se resistiram à erosão dos tempos. 